Manuscript for: Hydrometallurgy

N.K. Batchu, K. Binnemans

Hydrometallurgy 177, 146-151 (2018).

DOI: 10.1016/j.hydromet.2018.03.012

\title{
Effect of the diluent on the solvent extraction of neodymium(III) by bis(2-ethylhexyl)phosphoric acid (D2EHPA)
}

Nagaphani Kumar Batchu, ${ }^{\mathrm{a}}$ and Koen Binnemans ${ }^{\mathrm{a} *}$

${ }^{a}$ KU Leuven, Department of Chemistry, Celestijnenlaan 200 F, bus 2404, B-3001, Heverlee (Belgium)

\footnotetext{
* Corresponding author

E-mail: Koen.Binnemans@kuleuven.be
}

Phone: +3216 327446 


\begin{abstract}
The effect of different types of diluents on the extraction of neodymium(III) from a chloride aqueous feed solution by the acidic extractant bis(2-ethylhexylphosphoric) acid (D2EHPA) was investigated. A total of 11 aliphatic, mixed aliphatic-aromatic and aromatic diluents were considered. D2EHPA was very well miscible with all diluents, even at $90 \%(\mathrm{v} / \mathrm{v})$ of extractant. Aliphatic diluents gave the highest extraction efficiencies, while aromatic diluents did suppress the formation of emulsions or gels. Although a good separation of Dy(III) over $\mathrm{Nd}(\mathrm{III})$ was observed at $0.5 \mathrm{~mol} / \mathrm{L}$ D2EHPA in all diluents, aromatic diluents were found to yield the highest separation factors. This study shows that the effect of the diluent on the extraction behaviour of $\mathrm{Nd}(\mathrm{III})$ is primarily determined by the aliphatic/aromatic content of the diluent. Diluents with the same concentration of aromatics show very similar behaviour. The choice of a diluent can be based on factors other than the extraction behaviour, for instance price and volatility.
\end{abstract}

Keywords: D2EHPA; diluents; lanthanides; rare earths; solvent extraction 


\section{Introduction}

Solvent extraction is an important separation technique for mixtures of metals (Ritcey and Ashbrook, 1984; Ritcey and Ashbrook, 1979). The technique is based on the selective distribution of the metal ions between an aqueous phase and an immiscible organic phase. The organic phase consists of an extractant, a diluent and a modifier. The main roles of the diluent are to dissolve the extractant (and modifier), to modify the concentration of the extractant in the organic phase and to reduce the viscosity of the extractant. Diluents also help to reduce the tendency of the emulsification of the extractant. Likewise, they improve the dispersion and coalescence properties of the solvent. The diluent must be a good solvent for the extractant, the modifier and the extracted species. It must have a very low solubility in the aqueous phase, a low volatility, a high flash point, a low surface tension, and it must be economic and readily available.

It is often assumed that the diluent merely acts as a solvent for the extractant and that it has no active role in the extraction process. However, the diluent can have a large effect on the distribution ratios (Marcus, 1989). The extraction of the metal to the organic phase is influenced by the physical properties of the diluent: density, viscosity, dielectric constant and solubility parameters (Reichardt, 2003). In general, aromatic diluents have higher densities than aliphatic diluents, which may impede the dispersion and coalescence. The polarity of the diluent has a considerable effect on the extraction efficiencies. In general, extractants are polymerised or self-associated in non-polar solvents and occur as monomers in polar solvents (Berthon et al., 2010; Chiarizia et al., 2001). The average degree of polymerisation increases with a decrease in polarity of the diluent. The presence of polymeric forms decreases the loading capacity of the extractant. The interaction of the diluent with the extractant can 
decrease the extraction efficiency, since the formation of extractant-diluent species results in a lower concentration of free extractant. Diluents affect the solvation of the extractant and, hence, its extractive properties.

In many cases, the distribution ratios cannot be correlated to the physical properties of the diluent, even though many attempts have been made to do so. Taube tried to correlate the extraction efficiency of uranium, plutonium and neptunium with the dipole moment and the dielectric constant of the solvent (Taube, 1959, 1960). Healy (1961) linked the diluent effect with the water content of the solvents. The effect of diluents on the solvent extraction of metal ions has been studied for copper(II) (Whewell et al., 1979; Wionczyk and Apostoluk, 1997; Tao and Nagaosa, 2003; Mitchell and Banks, 1969), cobalt(II) (Aly et al., 1979), nickel(II) (Rajab et al., 1987; Rezaei and Nedjate, 2003; Sun et al., 2000), iron(III) (Alguacil et al., 1987; Cai et al., 2016; Mountcastle et al., 1971), aluminium(III) (Bailey and Mahi, 1987), trivalent rare earths (Arichi et al., 2006; Cui et al., 2012; Dukov and Atanassova, 2003; El-Nadi, 2010; Pai et al., 1977; Rout et al., 2012), thorium (Siekierski, 1962), uranium (Sato et al., 1985; Shukla and Kedari, 1996) and trivalent actinides (Chiarizia and Horwitz, 1992; Ekberg et al., 2010, 2015).

Lofstrom-Engdahl et al. (2013, 2014a, 2014b, 2014c) investigated in detail the effect of the diluent on the extraction of americium(III) and europium(III) by bis-triazine-bipyridine extractants. Recently, Gergoric et al. (2017b) investigated the effect of the diluents Solvent 70, hexane, octane, cyclohexanone, chloroform, 1-octanol, and toluene on the extraction of the rare earths $\mathrm{Pr}, \mathrm{Nd}, \mathrm{Gd}$ and Dy by the extractant bis(2-ethylhexyl)phosphoric acid (D2EHPA) from sulfuric acid feed solution, with an emphasis on the separation of light from heavy rare earths. The authors concluded that the aliphatic diluents hexane, octane and Solvent 70 were the most suitable diluents for solvent extraction of rare earths with D2EHPA. The more polar diluents cyclohexanone, chloroform and 1-octanol exhibited the 
lowest distribution ratios. Toluene showed an intermediate behaviour. In a follow-up paper, the authors investigated the extraction of rare earths by the solvating extractant tetraoctyldiglycolamide (TODGA) in the same diluents (Gergoric et al., 2017a). The highest separation factor for the separation of Dy from Nd and Pr was obtained for Solvent 70.

The objective of this paper is to study the effect of different diluents on the extraction behaviour of neodymium(III) from chloride aqueous solutions by the acidic extractant bis(2ethylhexyl)phosphoric acid (D2EHPA) (Figure 1). Neodymium(III) was selected as a representative rare-earth ion while D2EHPA is a commonly used extractant for rare-earth ions (Xie et al., 2014; Mohammadi et al., 2015; Peppard et al., 1957; Sato, 1989; Yin et al., 2016; Zheng et al., 1991). The separation of dysprosium(III) from neodymium(III) was investigated because this separation is relevant for the recycling of rare earths from $\mathrm{NdFeB}$ permanent magnets. A total of 11 diluents were considered. The diluents were either aliphatic solvents, mixed aliphatic-aromatic solvents or aromatic solvents. Halogenated organic solvents were not taken into account because of environmental issues. Furthermore, they are heavier than water.<smiles>CCCCC(CC)COP(=O)(O)OCC(CC)CCCC</smiles>

Figure 1. Structure of the extractant bis(2-ethylhexyl)phosphoric acid (D2EHPA). 


\section{Experimental details}

\section{Reagents and solutions}

$\mathrm{NdCl}_{3} \cdot 6 \mathrm{H}_{2} \mathrm{O}\left(99.9 \%\right.$ ) was purchased from Alfa Aesar (Ward Hill, USA) and $\mathrm{DyCl}_{3} \cdot 6 \mathrm{H}_{2} \mathrm{O}$ (99.9\%) from abcr GmbH. Bis(2-ethylhexyl) phosphoric acid (D2EHPA, 95\%) and $n$ dodecane (>99\%) were procured from Acros Organics (Geel, Belgium), while toluene was obtained from Sigma-Aldrich (Diegem, Belgium). A silicone solution in isopropanol (SERVA, Electrophoresis GmbH, Heidelberg, Germany) was used to siliconise the TXRF carriers. The praseodymium standard was purchased from Chem-Lab NV (Zedelgem, Belgium). The diluents were obtained from Shell Global Solutions (Amsterdam, The Netherlands). All chemicals were used as received, without any further purification.

\section{Instrumentation}

A benchtop total-reflection X-ray fluorescence (TXRF) spectrometer (S2 Picofox model, Bruker) was used to determine the metal concentrations before and after solvent extraction. Batch-mode extraction experiments were carried out by mixing two phases using a flat magnetic stirrer (MIX 15 eco model, 2 mag magnetic ${ }^{\mathrm{e}}$ motion).

\section{Solvent extraction procedure}

Extraction experiments were performed with the extractant bis(2-ethylhexyl)phosphoric acid (D2EHPA) diluted in the different diluents. For the extraction experiments of $\mathrm{Nd}(\mathrm{III})$ from chloride solutions, an initial stock solution $(0.069 \mathrm{~mol} / \mathrm{L})$ was prepared by dissolving $\mathrm{NdCl}_{3} \cdot 6 \mathrm{H}_{2} \mathrm{O}$ in distilled water. The experimental feed solution was prepared by diluting the stock solution to $0.0069 \mathrm{~mol} / \mathrm{L}$ and $\mathrm{NaCl}$ was used to keep the ionic strength at $1 \mathrm{~mol} / \mathrm{L}$. For 
the $\mathrm{Nd}(\mathrm{III}) / \mathrm{Dy}(\mathrm{III})$ separation experiments, a feed solution containing $[\mathrm{Nd}(\mathrm{III})]=0.025$

$\mathrm{mol} / \mathrm{L}$ and $[\mathrm{Dy}(\mathrm{III})]=0.028 \mathrm{~mol} / \mathrm{L}$ concentration was used. The exact $\mathrm{Nd}(\mathrm{III})$ and $\mathrm{Dy}(\mathrm{III})$ concentrations were determined by TXRF. Solvent extraction experiments were performed at $20{ }^{\circ} \mathrm{C}$ by mixing equal volumes of two phases in glass vials using a magnetic stirrer at 800 rpm. When equilibrium was reached, the mixture was separated and the equilibrium $\mathrm{pH}$ of the aqueous phase was measured. The metal concentration in the aqueous solution was determined by a TXRF spectrometer after adding a praseodymium internal standard. The metal concentration in the organic phase was obtained by the difference between the feed and raffinate concentrations. The quartz glass sample carriers for TXRF measurements were pretreated with $30 \mu \mathrm{L}$ of a silicone solution in isopropanol and dried in an oven for 2 min at $60{ }^{\circ} \mathrm{C}$. Subsequently, a sample of $2 \mu \mathrm{L}$ was added to the quartz glass carrier and dried at 60 ${ }^{\circ} \mathrm{C}$ for $20 \mathrm{~min}$. The samples were measured for $300 \mathrm{~s}$ in a TXRF spectrometer. All samples were measured in duplicate.

The distribution ratio $(D)$ is defined as the ratio of the metal concentration in the organic phase to that in the aqueous phase, at equilibrium. It can be expressed as:

$D=\frac{[M]_{0}-[M]_{a q}}{[M]_{a q}} \times \frac{V_{a q}}{V_{\text {org }}}$

where $[M]_{0}$ is the initial metal ion concentration in the aqueous phase. $[M]_{a q}$ represents the metal ion concentration in the aqueous phase after the extraction. $V_{a q}$ and $V_{\text {org }}$ are the volumes of aqueous and organic phases. The percentage extraction $(\% E)$ is defined as the amount of metal ion extracted to the organic phase versus the initial amount of metal ion. It can be expressed as: 
$\% E=\frac{[M]_{0}-[M]_{a q}}{[M]_{0}} \times 100$

The separation factor (SF) $\beta$ can be defined as the ratio of the distribution ratios of metals $\mathrm{A}$ and $\mathrm{B}\left(\right.$ where $\left.D_{A} \geq D_{B}\right)$ :

$$
\beta_{A, B}=\frac{D_{A}}{D_{B}}
$$

\section{Results and Discussion}

An overview of the diluents used in this study is provided in Table 1. The diluents can be categorised into three groups. Group I are aliphatic diluents: Shell GTL solvent GS190 (FTS-A), Shell GTL solvent GS215 (FTS-B), Shell GTL solvent GS250 (FTS-C), Shell GTL Fluid G70 (FTF-A), ShellSol D70 (D70), ShellSol D80 (D80), n-dodecane (DD). Group II represents mixed aliphatic-aromatic diluents: ShellSol 2325 (MS-A), ShellSol 2046AR (MSB), while Group III includes the aromatic diluents ShellSol A150 (A150) and toluene. The Fischer-Tropsch solvents FTS-A, FTS-B and FTS-C are mixtures of isoparaffins and normal paraffins, with a low content of naphthenes and a very low concentration of aromatics. These three solvents differ from each other with respect to their specific boiling range (although this is relatively small for all three). Fischer-Tropsch fluid A (FTF-A) has a composition that is similar to that of the Fischer-Tropsch solvents, but with a much larger boiling range. The aliphatic mineral spirits D70 and D80 contain much more naphthenes with respect to the Fischer-Tropsch solvents, but still exhibit a low concentration of aromatics. The mineral spirits MS-A and MS-B are mixed aliphatic-aromatic solvents with 15 to $19 \mathrm{wt} \%$ aromatics. 
Table 1. Overview of diluents used in this study and their composition.

\begin{tabular}{|c|c|c|c|c|c|}
\hline Diluent & Diluent type & & Composition & & Boiling \\
\hline & & $\begin{array}{l}\text { Paraffins } \\
(\mathrm{wt} \%) \\
\text { iso+n }\end{array}$ & $\begin{array}{l}\text { Naphthenes } \\
\text { (wt\%) }\end{array}$ & Aromatics & \\
\hline FTS-A & $\begin{array}{l}\text { Fischer- } \\
\text { Tropsch } \\
\text { solvent A }\end{array}$ & 97 & 3 & $<100 \mathrm{mg} / \mathrm{kg}$ & $187-218$ \\
\hline FTS-B & $\begin{array}{l}\text { Fischer- } \\
\text { Tropsch } \\
\text { solvent B }\end{array}$ & 98 & 2 & $<100 \mathrm{mg} / \mathrm{kg}$ & $218-247$ \\
\hline FTS-C & $\begin{array}{l}\text { Fischer- } \\
\text { Tropsch } \\
\text { solvent C }\end{array}$ & 98 & 2 & $<100 \mathrm{mg} / \mathrm{kg}$ & $253-270$ \\
\hline FTF-A & $\begin{array}{l}\text { Fischer- } \\
\text { Tropsch fluid } \\
\text { A }\end{array}$ & 98 & 2 & $<100 \mathrm{mg} / \mathrm{kg}$ & $179-323$ \\
\hline D70 & $\begin{array}{l}\text { Aliphatic } \\
\text { mineral spirit } \\
\text { D70 }\end{array}$ & 50 & 50 & $<100 \mathrm{mg} / \mathrm{kg}$ & $203-237$ \\
\hline D80 & $\begin{array}{l}\text { Aliphatic } \\
\text { mineral spirit } \\
\text { D80 }\end{array}$ & 31 & 69 & $<0.5 \mathrm{wt} \%$ & $212-295$ \\
\hline MS-A & $\begin{array}{l}\text { Mineral spirit } \\
\text { A }\end{array}$ & 44 & 35 & $15 \mathrm{wt} \%$ & $217-241$ \\
\hline MS-B & $\begin{array}{l}\text { Mineral spirit } \\
\text { B }\end{array}$ & 43 & 42 & $19 \mathrm{wt} \%$ & $212-271$ \\
\hline A150 & $\begin{array}{l}\text { Aromatic } \\
\text { solvent A } 150\end{array}$ & 0 & 0 & $>99 \mathrm{wt} \%$ & $185-198$ \\
\hline toluene & toluene & 0 & 0 & 100 & $100-111$ \\
\hline $\mathrm{DD}$ & $n$-dodecane & 100 & 0 & 0 & $216-217$ \\
\hline
\end{tabular}


In order to find the maximum concentration that can be prepared in the investigated diluents, the solubility of bis(2-ethylhexyl)phosphoric acid (D2EHPA) was tested in all commercial diluents and pure solvents ( $n$-dodecane and toluene). Experiments were conducted in test tubes by increasing the D2EHPA content in the diluents: 35, 70 and $90 \%$ (v/v). D2EHPA was miscible with all diluents in all tested volume ratios.

In a first series of extraction experiments, the effect of the equilibrium $\mathrm{pH}$ on the extraction of $\mathrm{Nd}(\mathrm{III})$ was investigated. Using an aqueous $\mathrm{HCl}$ solution, the equilibrium $\mathrm{pH}$ was varied from 1.6 to 1.0 for FTS-A, MS-B and 1.8 to 1.0 for A150 diluents. The equilibration time was $30 \mathrm{~min}$. The distribution ratios of $\mathrm{Nd}(\mathrm{III})$ increased with increasing equilibrium $\mathrm{pH}$, using $1 \mathrm{~mol} / \mathrm{L}$ D2EHPA (Figure 2). The distribution ratio (and thus also the percentage extraction) was higher in aliphatic diluents than in aromatic or in mixed aliphaticaromatic diluents. It was observed that the distribution ratios of $\mathrm{Nd}(\mathrm{III})$ using $1 \mathrm{~mol} / \mathrm{L}$ D2EHPA were very similar ( 22.8 at equilibrium $\mathrm{pH} 1.6)$ in all aliphatic diluents, i.e. about 8.6 (at equilibrium $\mathrm{pH}$ 1.6) in mixed aliphatic-aromatic diluents and approximately 1.6 in aromatic diluents (at equilibrium $\mathrm{pH}$ 1.8). The order of extraction can be given as: (FTS-A, FTS-B, FTS-C, FTF-A, D70, D80) > (MS-A, MS-B) > A150. This implies that the order of the extraction is as follows: aliphatic diluents > mixed aliphatic-aromatic diluents $>$ aromatic diluents. Several authors have observed a similar trend for the effect of the diluent on the extraction of rare earths, i.e. higher distribution ratios in aliphatic diluents than in aromatic diluents (Cui et al., 2012; Gergoric et al., 2017a, 2017b; El-Nadi, 2010). The general rule is that a higher dielectric constant $\varepsilon$ and a higher dipole moment lead to an increase in extraction efficiency. This is explained by the fact that the interaction between the extractant molecules and the diluent molecules are stronger if the dielectric constant of the diluent is higher. This stronger interaction results in a weaker extraction of metal ions. 


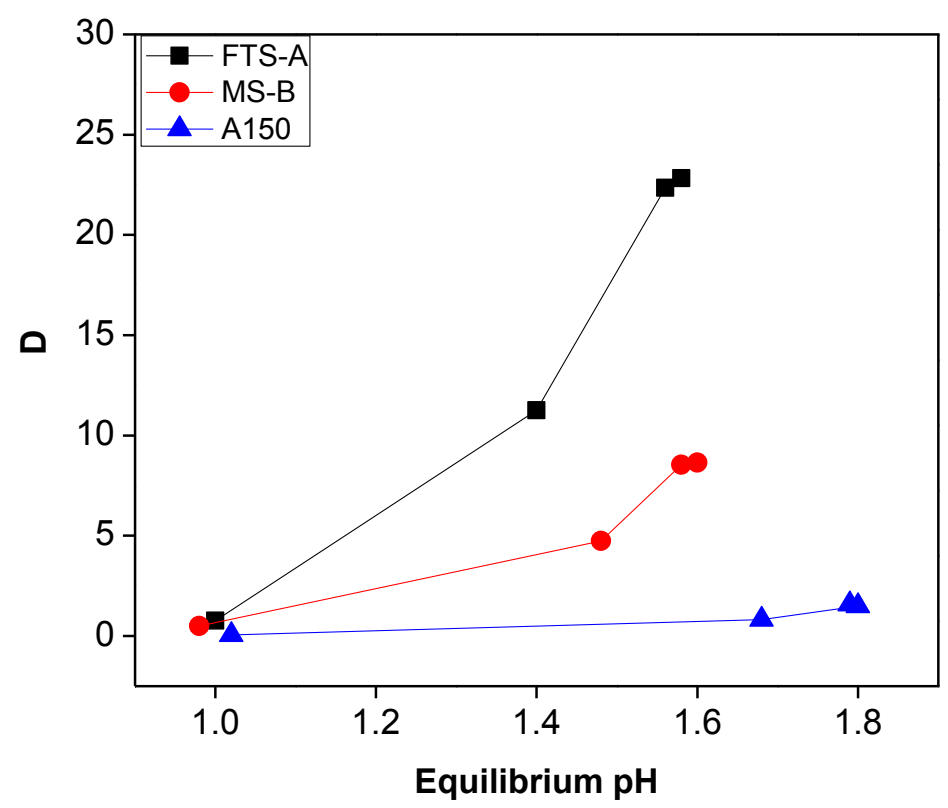

Figure 2. Effect of the equilibrium $\mathrm{pH}$ on the extraction of $\mathrm{Nd}(\mathrm{III})$ from a chloride solution using $1 \mathrm{~mol} / \mathrm{L}$ D2EHPA in selected diluents (FTS-A, MS-B, A150). Experimental conditions: $[N d(I I I)]=6.29 \times 10^{-3} \mathrm{~mol} / \mathrm{L},[\mathrm{NaCl}]=1 \mathrm{~mol} / \mathrm{L},[D 2 E H P A]=1 \mathrm{~mol} / \mathrm{L}$, equilibration time $:$ 30 min , temperature: $20^{\circ} \mathrm{C}$.

Taking into account that the extraction kinetics are an important parameter in the optimisation of a solvent extraction process, the effect of the equilibration time on the extraction of $\mathrm{Nd}(\mathrm{III})$ using $0.05 \mathrm{~mol} / \mathrm{L}$ D2EHPA was studied. Equilibrium was reached within 5 minutes for all diluents tested. The results for selected diluents (FTS-A, MS-B, A150) are shown in Figure 3. The curves for the other diluents are very similar. The nature of the diluent does not have a significant effect on the equilibration time.

The phase disengagement time was measured during the solvent extraction experiments by varying the $\mathrm{Nd}(\mathrm{III})$ concentration between $0.035 \mathrm{~mol} / \mathrm{L}$ and $0.69 \mathrm{~mol} / \mathrm{L}$. The data provided in Table 2 represent the averages of triplicate measurements. These results corroborate that the two phases get separated rapidly in all diluents; 1 to 1.5 minutes suffice 
for complete phase separation (Table 2). Phase separation was the slowest in the D80 diluent and the fastest in MS-B. This implies that a certain amount of aromatic compounds in the aliphatic diluents boosts the phase separation. On the other hand, the diluent with a higher amount of naphthenes exhibits a longer phase disengagement time.

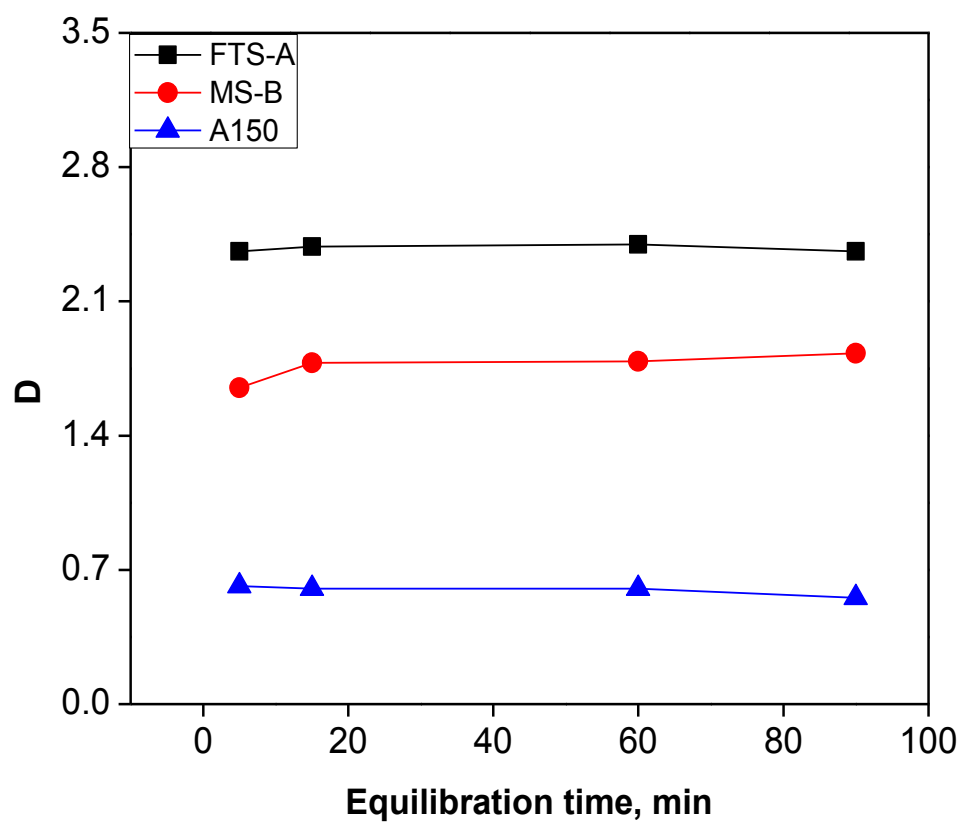

Figure 3. Effect of equilibration time on the extraction of $N d(I I I I)$ from chloride solutions using $0.05 \mathrm{~mol} / \mathrm{L}$ D2EHPA in selected diluents (FTS-A, MS-B, A150). Experimental conditions: $[\mathrm{Nd}(\mathrm{III})]=6.45 \times 10^{-3} \mathrm{~mol} / \mathrm{L},[\mathrm{NaCl}]=1 \mathrm{~mol} / \mathrm{L},[\mathrm{D} 2 \mathrm{EHPA}]=0.05 \mathrm{~mol} / \mathrm{L}$, equilibration time: $0-90$ min, temperature: $20^{\circ} \mathrm{C}$. 
Table 2. Measurement of phase disengagement time (in seconds) as a function of the metal concentration for different diluents.

\begin{tabular}{lllll}
\hline [Nd], mol/L & 0.035 & 0.069 & 0.35 & 0.69 \\
\hline FTS-A & 40 & 38 & 40 & 40 \\
FTS-B & 60 & 52 & 45 & 60 \\
FTF-A & 50 & 60 & 65 & 50 \\
D80 & 78 & 80 & 80 & 85 \\
$n$-DD & 55 & 52 & 56 & 50 \\
MS-B & 40 & 38 & 37 & 38 \\
A150 & 52 & 45 & 50 & 55 \\
toluene & 46 & 45 & 46 & 50 \\
\hline
\end{tabular}

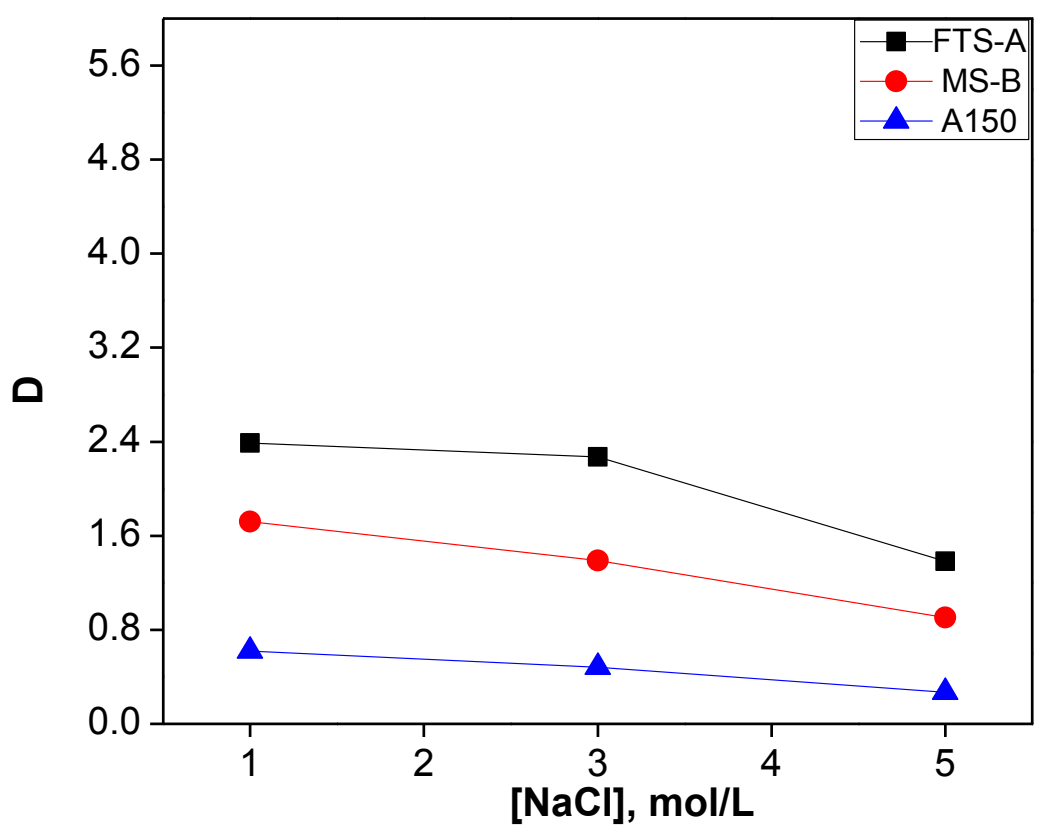

Figure 4. Effect of the sodium chloride concentration on the extraction of $N d(I I I)$ using D2EHPA in selected diluents (FTS-A, MS-B, A150). Experimental conditions: $[N d(I I I)]=$ $6.93 \times 10^{-3} \mathrm{~mol} / \mathrm{L},[\mathrm{NaCl}]=1-5 \mathrm{~mol} / \mathrm{L},[\mathrm{D} 2 \mathrm{EHPA}]=0.05 \mathrm{~mol} / \mathrm{L}$, equilibration time $: 30$ min, temperature: $20^{\circ} \mathrm{C}$. 
Concurrently, the effect of the chloride ion on the extraction of $\mathrm{Nd}(\mathrm{III})$ was studied by varying the chloride ion concentration from 1 to $5 \mathrm{~mol} / \mathrm{L}$, using $\mathrm{NaCl}$ at fixed $\mathrm{pH}$ and extractant concentration in all diluents. In Figure 4, some selected results are shown. The chloride ion concentration was found to have a marginal effect on the extraction of $\mathrm{Nd}(\mathrm{III})$.

The effect of the D2EHPA concentration in the different diluents on the extraction of $\mathrm{Nd}(\mathrm{III})$ from the chloride solution containing $6.93 \times 10^{-3} \mathrm{~mol} / \mathrm{L}$ of $\mathrm{Nd}(\mathrm{III})$ and $1 \mathrm{~mol} / \mathrm{L} \mathrm{NaCl}$ was studied by increasing the D2EHPA concentration from 0.01 to $0.1 \mathrm{~mol} / \mathrm{L}$ (Table 3 ). The change in equilibrium pH was 2.1-1.6 in aliphatic diluents (FTS-A and FTS-B) and 2.4-1.8 in aromatic diluents (A150). As expected, the distribution ratios of $\mathrm{Nd}(\mathrm{III})$ increased with higher D2EHPA concentrations.

The effect of the metal concentration on the loading of $1 \mathrm{~mol} / \mathrm{L}$ D2EHPA was investigated for different feed solutions with distinct concentrations of $\mathrm{Nd}(\mathrm{III})$ : $0.035,0.069$, 0.35, $0.69 \mathrm{~mol} / \mathrm{L}$ (Figures 5 and 6). The percentage extraction of $\mathrm{Nd}(\mathrm{III})$ decreased with increasing initial metal concentration. The maximum loading capacity of $1 \mathrm{~mol} / \mathrm{L}$ D2EHPA for $\mathrm{Nd}(\mathrm{III})$ from chloride solutions is $0.09 \pm 0.007 \mathrm{~mol} / \mathrm{L}$ (which is about $29 \%$ of the theoretical loading capacity) for aliphatic diluents, $0.08 \pm 0.003 \mathrm{~mol} / \mathrm{L}$ (approximately $25 \%$ of the theoretical loading capacity) for MS-B, and $0.06 \pm 0.003 \mathrm{~mol} / \mathrm{L}$ (about $19 \%$ of the theoretical loading capacity) for A150 and toluene. The loading capacity of $1 \mathrm{~mol} / \mathrm{L}$ D2EHPA was studied as a function of the volume phase ratio at a fixed concentration of 0.35 $\mathrm{mol} / \mathrm{L}$ of $\mathrm{Nd}(\mathrm{III})$ in the feed phase (Figure 7). The solvents follow a similar trend. The aqueous-to-organic phase ratio was increased from 0.33 to 7 . Gel formation was observed above the 1:1 phase ratio for the aliphatic solvents. Aromatic diluents did not form gel at any of the studied phase ratios. In mixed aliphatic-aromatic diluents the tendency for gel 
formation decreased as the aromatic content of the diluent increased. Gel formation can be explained by the aggregation of metal-ligand complexes and subsequent polymerisation. Antico et al. (1996) reported the formation of gels in the extraction of Y(III) from chloride solutions by D2EHPA diluted in kerosene. D2EHPA formed gels at lower acid concentrations when the concentration ratio of Y(III):D2EHPA was 1:2.2 to 1:9.9. The present results are in agreement with these findings. The tendency of D2EHPA to form gels at high loading of the organic phase by rare-earth ions, when using kerosene as diluent, is a well known phenomenon, which is considered as a disadvantage of this extractant when using it for separation of rare earths (Antico et al., 1996).

Table 3. Effect of D2EHPA concentration on the extraction of Nd(III).

\begin{tabular}{|c|c|c|c|c|c|c|c|c|c|}
\hline $\begin{array}{l}\text { [D2EHPA], } \\
\mathrm{mol} / \mathrm{L}\end{array}$ & $\begin{array}{l}D_{N d}, \\
\text { (FTS- } \\
\text { A) }\end{array}$ & $\begin{array}{l}D_{N d}, \\
(\mathrm{FTS}- \\
\text { B) }\end{array}$ & $\begin{array}{l}D_{N d}, \\
(\mathrm{FTS}- \\
\mathrm{C})\end{array}$ & $\begin{array}{l}D_{N d}, \\
(\mathrm{FTL}- \\
\mathrm{A})\end{array}$ & $\begin{array}{l}D_{N d}, \\
(\mathrm{D} 80)\end{array}$ & $\begin{array}{l}D_{N d}, \\
(\mathrm{D} 70)\end{array}$ & $\begin{array}{l}D_{N d}, \\
(\mathrm{MS}- \\
\mathrm{A})\end{array}$ & $\begin{array}{l}D_{N d}, \\
(\mathrm{MS}- \\
\mathrm{B})\end{array}$ & $\begin{array}{l}D_{N d}, \\
(\mathrm{~A} 150)\end{array}$ \\
\hline 0.01 & 0.5 & 0.5 & 0.5 & 0.5 & 0.4 & 0.4 & 0.3 & 0.3 & 0.2 \\
\hline 0.03 & 1.1 & 1.2 & -- & -- & 1.0 & -- & 0.7 & 0.9 & 0.4 \\
\hline 0.05 & 2.4 & 2.5 & 3.0 & 3.2 & 2.2 & 2.3 & 1.7 & 1.7 & 0.6 \\
\hline 0.1 & 16.7 & 21.1 & 22.0 & 19.3 & 15.6 & 16.4 & 7.5 & 8.1 & 1.4 \\
\hline
\end{tabular}




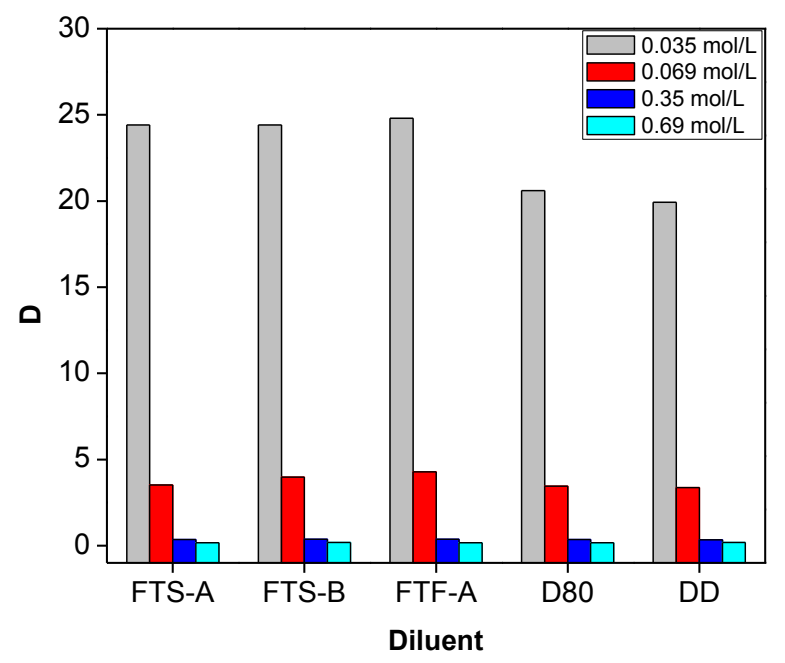

Figure 5. Effect of $N d(I I I)$ concentration on the extraction of $N d(I I I)$ from chloride solutions in aliphatic diluents. Experimental conditions: $[\mathrm{Nd}(\mathrm{III})]=0.035-0.69 \mathrm{~mol} / \mathrm{L},[\mathrm{NaCl}]=1$ $\mathrm{mol} / \mathrm{L},[D 2 E H P A]=1 \mathrm{~mol} / \mathrm{L}$ in the diluent, equilibration time: 30 min, temperature: $20^{\circ} \mathrm{C}$.

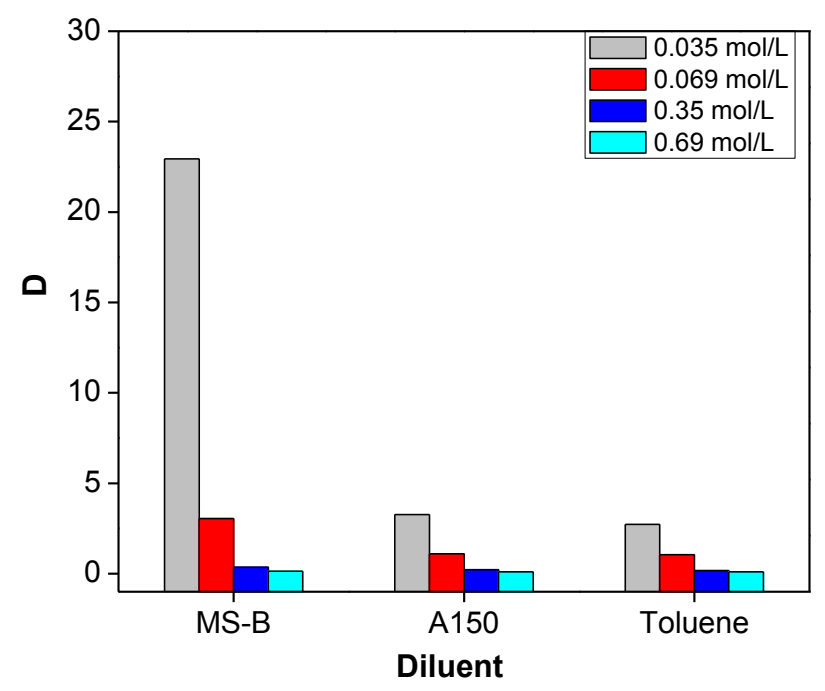

Figure 6. Effect of $N d(I I I)$ concentration on the percentage extraction of $N d(I I I)$ from chloride solutions in mixed aliphatic-aromatic and aromatic diluents. Experimental conditions: $[N d(I I I)]=0.035-0.69 \mathrm{~mol} / \mathrm{L},[\mathrm{NaCl}]=1 \mathrm{~mol} / \mathrm{L},[D 2 E H P A]=1 \mathrm{~mol} / \mathrm{L}$ in $M S-$ $B, A 150$ and toluene, equilibration time: 30 min, temperature: $20^{\circ} \mathrm{C}$. 


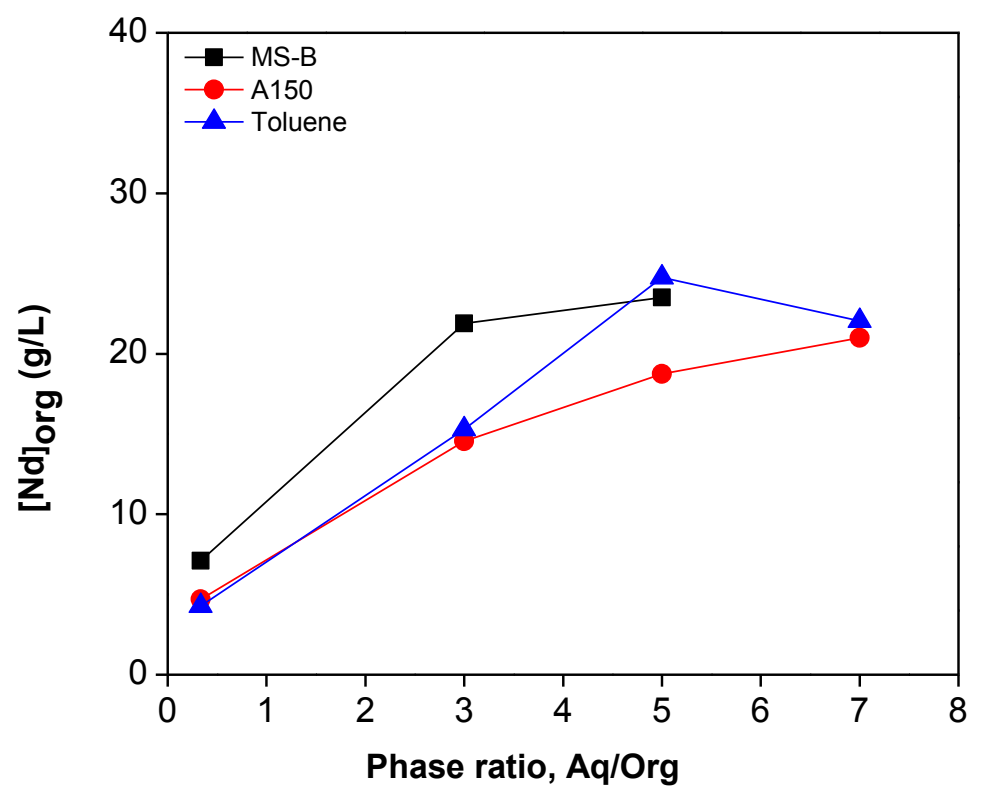

Figure 7. Effect of the phase ratio on the loading of $1 \mathrm{~mol} / \mathrm{L}$ D2EHPA from chloride solutions in mixed aliphatic-aromatic and aromatic diluents. Experimental conditions: $[N d(I I I)]=$ $0.35 \mathrm{~mol} / \mathrm{L},[\mathrm{D} 2 \mathrm{EHPA}]=1 \mathrm{~mol} / \mathrm{L}$ in $M S-B, A 150$ and toluene, equilibration time: $30 \mathrm{~min}$, temperature: $20^{\circ} \mathrm{C}$.

The effect of the D2EHPA concentration on the separation of Dy(III) and Nd(III) from chloride solutions was studied in the range of 0.1 to $1 \mathrm{~mol} / \mathrm{L}$ (Table 4 , Figure 8 ). The selected diluents were FTS-B, MS-B and A150. The extraction of Dy(III) and Nd(III) increased while increasing the D2EHPA concentration. The order of extraction of Dy(III) and Nd(III) follows the atomic number, which can be explained by considering the ionic radii and charge density of Dy(III) and $\mathrm{Nd}(\mathrm{III})$. The ionic radius of Dy(III) is smaller than that of $\mathrm{Nd}(\mathrm{III})$ due to the lanthanide contraction. Therefore, the charge density of Dy(III) is higher than that of $\mathrm{Nd}(\mathrm{III})$, which results in a more efficient extraction of Dy(III) compared to $\mathrm{Nd}(\mathrm{III})$ (Mohammadi et al., 2015; Gergoric et al., 2017b). The separation factors $\left(\beta=D_{\text {Dy(III) }} / D_{\mathrm{Nd}(\mathrm{III})}\right)$ increased while increasing the D2EHPA concentration up to a maximum of $0.5 \mathrm{~mol} / \mathrm{L}$ D2EHPA, and 
decreased for higher D2EHPA concentrations. A good separation of Dy(III) over Nd(III) was found at $0.5 \mathrm{~mol} / \mathrm{L}$ D2EHPA in all investigated diluents. From the separation factor values, it can be concluded that $\mathrm{A} 150$ is the best diluent for the separation of $\mathrm{Dy}(\mathrm{III})$ from $\mathrm{Nd}(\mathrm{III})$.

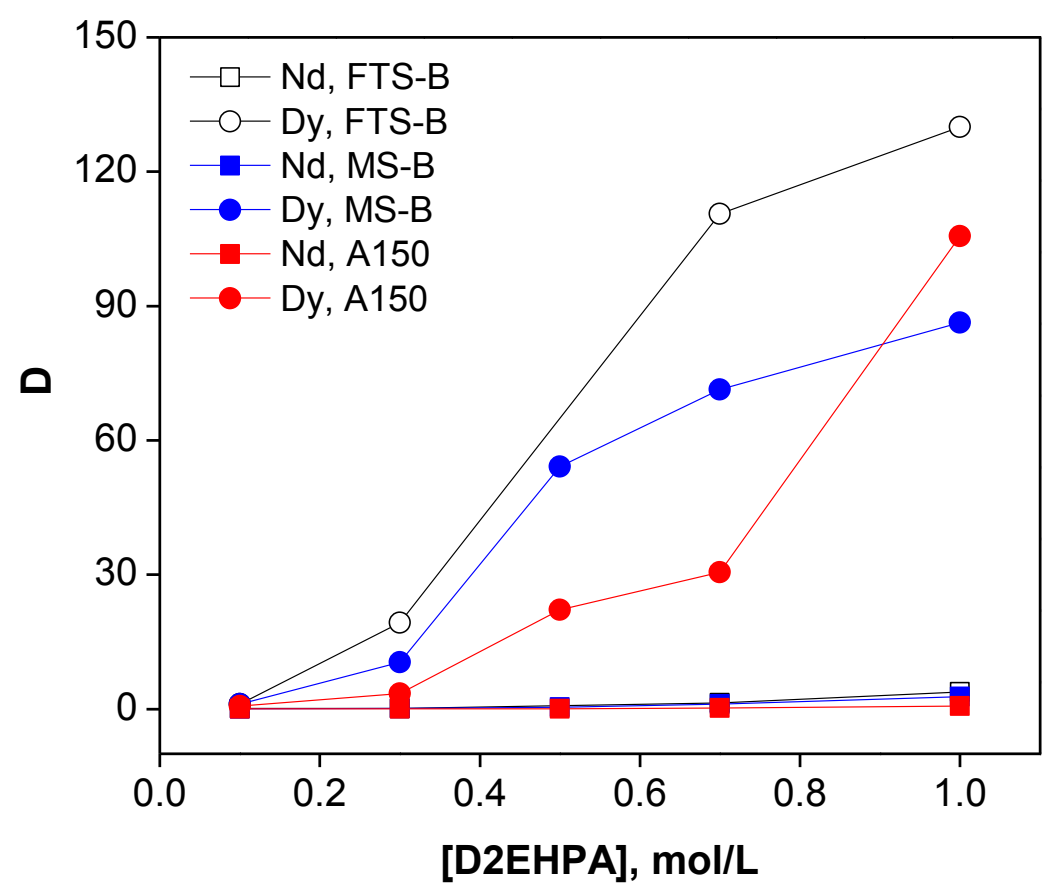

Figure 8. Effect of the D2EHPA concentration in selected diluents (FTS-B, MS-B and A150) on the percentage extraction of Dy(III) and $N d(I I I)$ from chloride solutions. Experimental conditions: $[\mathrm{Nd}(\mathrm{III})]: 0.025 \mathrm{~mol} / \mathrm{L},[\mathrm{Dy}(\mathrm{III})]: 0.028 \mathrm{~mol} / \mathrm{L}, \mathrm{NaCl}: 1 \mathrm{~mol} / \mathrm{L}$, equilibrium time: 30 min, temperature: $20^{\circ} \mathrm{C}$. 
Table 4. Comparison of separation factors for separation of Dy(III) over Nd(III).

\begin{tabular}{llll}
\hline [D2EHPA], & FTS-B & MS-B & A150 \\
mol/L & & & \\
\hline 0.1 & 7.8 & 15 & 45 \\
0.3 & 131 & 108 & 70 \\
0.5 & 202 & 136 & 254 \\
0.7 & 80 & 65 & 130 \\
1 & 34 & 32 & 161 \\
\hline
\end{tabular}

\section{Conclusions}

The objective of this study was to compare the performance of 11 different diluents for the solvent extraction of neodymium(III) from chloride aqueous feed solutions by bis(2ethylhexyl)phosphoric acid (D2EHPA). The diluents included different aliphatic, mixed aliphatic-aromatic and aromatic diluents. D2EHPA is very well miscible with all diluents, even at $90 \%(\mathrm{v} / \mathrm{v})$ of extractant. Aliphatic diluents provided higher extraction efficiencies, while aromatic diluents can suppress the formation of emulsions or gels. A good separation of Dy(III) over Nd(III) was observed at $0.5 \mathrm{~mol} / \mathrm{L}$ D2EHPA in all diluents. The aromatic diluent A150 was found to be the most performant diluent for the separation of Dy(III) from $\mathrm{Nd}(\mathrm{III})$. This study highlights that the effect of the diluent on the extraction behaviour of the system is primarily determined by the aliphatic/aromatic content of the diluent. Diluents with the same concentration of aromatics exhibit very similar behaviour. 


\section{Acknowledgments}

The authors acknowledge KU Leuven (projects GOA/13/008 and IOF-KP RARE ${ }^{3}$, and an F+ postdoctoral fellowship to NKB) for financial support. The authors wish to thank René Wiersma (Shell Global Solutions Int. B.V., Amsterdam, The Netherlands) for providing samples of the diluents and for scientific discussions. 


\section{References}

Alguacil, F., Amer, S., Luis, A., 1987. The influence of the diluent on the extraction of iron(III) from aluminium sulfate solutions by the amine Primene-81R sulfate. Hydrometallurgy 18, 65-73. doi:10.1016/0304-386X(87)90017-X

Aly, H., Raieh, M., Mohamed, S., Abdelrassoul, A., 1979. Influence of diluent on the synergic extraction of divalent cobalt by the thenoyltrifluoroacetone - tribenzylamine perchlorate system. J. Radioanal. Chem. 49, 213-224. doi:10.1007/BF02519912

Antico, E., Masana, A., Hidalgo, M., Salvado, V., Iglesias, M., Valiente, M., 1996. Solvent extraction of yttrium from chloride media by di(2-ethylhexyl)phosphoric acid in kerosene. Speciation studies and gel formation. Anal. Chim. Acta 327, 267-276. doi:10.1016/0003-2670(96)00103-1

Arichi, J., Goetz-Grandmont, G., Brunette, J.P., 2006. Solvent extraction of europium(III) from nitrate medium with 4-acyl-isoxazol-5-ones and 4-acyl-5-hydroxy-pyrazoles. Effect of salts and diluents. Hydrometallurgy 82, 100-109. doi:10.1016/j.hydromet.2006.04.004

Bailey, N., Mahi, P., 1987. The effect of diluents on the metal extracted and phase-separation in the extraction of aluminium with monononyl phosphoric acid. Hydrometallurgy 18, 351-365. doi:10.1016/0304-386X(87)90075-2

Berthon, L., Testard, F., Martinet, L., Zemb, T., Madic, C., 2010. Influence of the extracted solute on the aggregation of malonamide extractant in organic phases: Consequences for phase stability. Comptes Rendus Chim. 13, 1326-1334. doi:10.1016/j.crci.2010.03.024

Cai, X., Wei, B., Han, J., Li, Y., Cui, Y., Sun, G., 2016. Solvent extraction of iron(III) from hydrochloric acid solution by $\mathrm{N}, \mathrm{N}, \mathrm{N}$ `,N `-tetra-2-ethylhexyldiglycolamide in different diluents. Hydrometallurgy 164, 1-6. doi:10.1016/j.hydromet.2016.04.010

Chiarizia, R., Horwitz, E., 1992. Diluent effects in the extraction of Am(III) from nitric acid solutions by selected carbamoyl-phosphoryl extractants and related monofunctional compounds. Solvent Extr. Ion Exch. 10, 101-118. doi:10.1080/07366299208918094

Chiarizia, R., McAlister, D., Herlinger, A., 2001. Solvent extraction by dialkyl-substituted diphosphonic acids in a depolymerizing diluent. II. Fe(III) and actinide ions. Solvent Extr. Ion Exch. 19, 415-440. doi:10.1081/SEI-100103278

Cui, Y., Yang, J., Yang, G., Xia, G., Nie, Y., Sun, G., 2012. Effect of diluents on extraction behavior of rare earth elements with N,N,N ', `-tetrabutyl-3-oxy-glutaramide from hydrochloric acid. Hydrometallurgy 121, 16-21. doi:10.1016/j.hydromet.2012.04.013

Dukov, I., Atanassova, M., 2003. Effect of the diluents on the synergistic solvent extraction of some lanthanides with thenoyltrifluoroacetone and quaternary ammonium salt. Hydrometallurgy 68, 89-96. doi:10.1016/S0304-386X(02)00171-8

Ekberg, C., Aneheim, E., Fermvik, A., Foreman, M., Lofstrom-Engdahl, E., Retegan, T., Spendlikova, I., 2010. Thermodynamics of Dissolution for Bis(triazine)-BipyridineClass Ligands in Different Diluents and Its Reflection on Extraction. J. Chem. Eng. Data 55, 5133-5137. doi:10.1021/je1005246

Ekberg, C., Lofstrom-Engdahl, E., Aneheim, E., Foreman, M.R.S.J., Geist, A., Lundberg, D., Denecke, M., Persson, I., 2015. The structures of CyMe4-BTBP complexes of americium(III) and europium(III) in solvents used in solvent extraction, explaining their separation properties. Dalton Trans. 44, 18395-18402. doi:10.1039/c5dt02859k

Gergoric, M., Ekberg, C., Foreman, M.R.S.J., Steenari, B.-M., Retegan, T., 2017a. Characterization and Leaching of Neodymium Magnet Waste and Solvent Extraction of the Rare-Earth Elements Using TODGA. J. Sustain. Metall. 3, 638-645. doi:10.1007/s40831-017-0122-8 
El-Nadi, Y.A., 2010. Effect of diluents on the extraction of praseodymium and samarium by Cyanex 923 from acidic nitrate medium. J. Rare Earths 28, 215-220. doi:10.1016/S1002-0721(09)60083-1

Gergoric, M., Ekberg, C., Steenari, B.-M., Retegan, T., 2017b. Separation of Heavy RareEarth Elements from Light Rare-Earth Elements via Solvent Extraction from a Neodymium Magnet Leachate and the Effects of Diluents. J. Sustain. Metall. 3, 601610. doi:10.1007/s40831-017-0117-5

Healy, T., 1961. Synergism in the solvent extraction of divalent, trivalent and tetravalent metal ions - synergic effects in so-called inert diluents. J. Inorg. Nucl. Chem. 19, 328339. doi:10.1016/0022-1902(61)80122-X

Lofstrom-Engdahl, E., Aneheim, E., Ekberg, C., Elfverson, H., Foreman, M., Skarnemark, G., 2014a. Hexanoic acid as an alternative diluent in a GANEX process: feasibility study. J. Radioanal. Nucl. Chem. 299, 1261-1266. doi:10.1007/s10967-013-2861-8

Lofstrom-Engdahl, E., Aneheim, E., Ekberg, C., Foreman, M., Hallerod, J., Skarnemark, G., 2014b. Extraction thermodynamics of Am(III) and Eu(III) using CyMe4-BTBP in various organic diluents. J. Chem. Thermodyn. 76, 64-69. doi:10.1016/j.jct.2014.03.004

Lofstrom-Engdahl, E., Aneheim, E., Ekberg, C., Foreman, M., Skarnemark, G., 2014c. A Comparison of Americium Extractions as a Function of Time using Two BisTriazine-Bipyridine Ligands in Long-Chained Alcohol Diluents. Sep. Sci. Technol. 49, 2060-2065. doi:10.1080/01496395.2014.911325

Lofstrom-Engdahl, E., Aneheim, E., Ekberg, C., Skarnemark, G., 2013. A reinterpretation of C5-BTBP extraction data, performed in various alcohols. J. Radioanal. Nucl. Chem. 296, 733-737. doi:10.1007/s10967-012-1976-7

Marcus, Y., 1989. Diluent effects in solvent extraction. Solvent Extr. Ion Exch. 7, 567-575. doi:10.1080/07360298908962325

Mitchell, J., Banks, C., 1969. Solvent effects on solubilities and partition coefficients of some copper(II) beta-diketone complexes. J. Inorg. Nucl. Chem. 31, 2105-2115. doi:10.1016/0022-1902(69)90026-8

Mohammadi, M., Forsberg, K., Kloo, L., De La Cruz, J.M., Rasmuson, A., 2015. Separation of ND(III), DY(III) and Y(III) by solvent extraction using D2EHPA and EHEHPA. Hydrometallurgy 156, 215-224. doi:10.1016/j.hydromet.2015.05.004

Mountcastle, W., Martin, W., Ballard, P., Miles, D., 1971. Solvent extraction of acidic chloride solutions of iron(III) by phenylphosphonate diesters in various organic solvents. J. Inorg. Nucl. Chem. 33, 3537-3545. doi:10.1016/0022-1902(71)80675-9

Pai, S., Mathur, J., Khopkar, P., Subramanian, M., 1977. Thermodynamics of synergistic extraction of europium(III) with thenoyltrifluoroacetone and tributylphosphate in various diluents. J. Inorg. Nucl. Chem. 39, 1209-1211. doi:10.1016/00221902(77)80347-3

Peppard, D., Mason, G., Maier, J., Driscoll, W., 1957. Fractional extraction of the lanthanides as their di-alkyl orthophosphates. J. Inorg. Nucl. Chem. 4, 334-343. doi:10.1016/0022-1902(57)80016-5

Rajab, A., Pareau, D., Moulin, J., Chesne, A., 1987. Effect of solvent composition and solvent extraction of cobalt and nickel by di(2-ethylhexyl)phosphoric acid. Bull. Soc. Chim. Fr. 29-33.

Reichardt, C., 2003. Solvents and Solvent Effects in Organic Chemistry, Third Edition. ed. Wiley-VCH, Weinheim.

Rezaei, K., Nedjate, H., 2003. Diluent effect on the distribution ratio and separation factor of $\mathrm{Ni}(\mathrm{II})$ in the liquid-liquid extraction from aqueous acidic solutions using 
dibutyldithiophosphoric acid. Hydrometallurgy 68, 11-21. doi:10.1016/S0304386X(02)00168-8

Ritcey, G., Ashbrook, A., 1984. Solvent extraction : principles and applications to process metallurgy, Volume I. Elsevier, Amsterdam.

Ritcey, G., Ashbrook, A., 1979. Solvent extraction : principles and applications to process metallurgy, Volume II. Elsevier, Amsterdam.

Rout, A., Venkatesan, K.A., Srinivasan, T.G., Rao, P.R.V., 2012. Ionic liquid extractants in molecular diluents: Extraction behavior of europium(III) in quarternary ammoniumbased ionic liquids. Sep. Purif. Technol. 95, 26-31. doi:10.1016/j.seppur.2012.04.020

Sato, T., 1989. Liquid-liquid extraction of rare-earth elements from aqueous acid solutions by acid organo-phosphorus compounds. Hydrometallurgy 22, 121-140. doi:10.1016/0304-386X(89)90045-5

Sato, T., Nakamura, T., Kuwahara, M., 1985. Diluent effect on the extraction of uranium(VI) from hydrochloric acid solutions by trioctylamine. Solvent Extr. Ion Exch. 3, 283307. doi:10.1080/07366298508918513

Shukla, J., Kedari, C., 1996. Influence of the nature of organic diluents on the extraction of uranium(VI) by bis(2-ethylhexyl) sulfoxide from nitric acid solutions. J. Radioanal. Nucl. Chem.-Artic. 207, 93-105. doi:10.1007/BF02036529

Siekierski, S., 1962. The influence of diluent on extraction of europium and thorium nitrates by tri-normal-butylphosphate. J. Inorg. Nucl. Chem. 24, 205-214. doi:10.1016/S00221902(62)90336-6

Sun, G., Cui, Y., Sun, S., Yang, Y., Yang, Y., 2000. Interfacial activity of HDEHP and kinetics of nickel extraction in various diluents. Solvent Extr. Ion Exch. 18, 517-531.

Tao, W., Nagaosa, Y., 2003. Solvent extraction of copper (II) with di-2methylnonylphosphoric acid in some organic diluents. Solvent Extr. Ion Exch. 21, 273-290. doi:10.1081/SEI-120018950

Taube, M., 1960. The influence of diluent polarity on the extraction of neptunium and uranium compounds to organic media. J. Inorg. Nucl. Chem. 15, 171-176. doi:10.1016/0022-1902(60)80025-5

Taube, M., 1959. The influence of diluent polarity on extraction of plutonium complexes to organic media. J. Inorg. Nucl. Chem. 12, 174-180. doi:10.1016/0022-1902(59)80107$\mathrm{X}$

Whewell, R., Hughes, M., Middlebrook, P., 1979. Modeling of equilibrium data for the liquid-liquid extraction of metals. 4. Effect of diluent on the copper-LIX 64N system. Hydrometallurgy 4, 125-133. doi:10.1016/0304-386X(79)90041-0

Wionczyk, B., Apostoluk, W., 1997. Analysis of diluent effects and estimation of distribution constants of 8-hydroxyquinoline and its derivatives in extraction systems. Hydrometallurgy 45, 73-81. doi:10.1016/S0304-386X(96)00082-5

Xie, F., Zhang, T.A., Dreisinger, D., Doyle, F., 2014. A critical review on solvent extraction of rare earths from aqueous solutions. Miner. Eng. 56, 10-28. doi:10.1016/j.mineng.2013.10.021

Yin, S., Li, S., Zhang, B., Peng, J., Zhang, L., 2016. Extraction kinetics of neodymium(III) from chloride medium in the presence of two complexing agents by D2EHPA using a constant interfacial area cell with laminar flow. Hydrometallurgy 161, 160-165. doi:10.1016/j.hydromet.2016.01.016

Zheng, D., Gray, N., Stevens, G., 1991. Comparison of naphthenic acid, versatic acid and D2EHPA for the separation of rare earths. Solvent Extr. Ion Exch. 9, 85-102. doi:10.1080/07366299108918044 